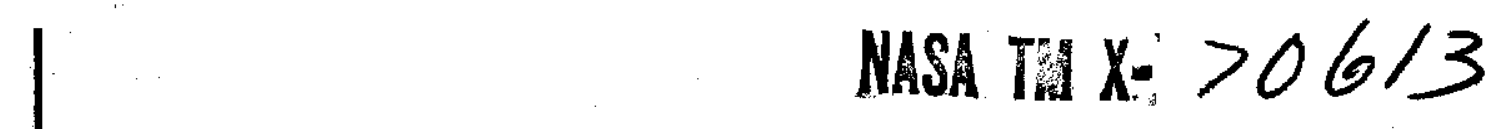

\title{
ELECTRIC FIELD MEASUREMENTS ACROSS THE HARANG DISCONTINUITY
}

(NASA-TI-X-70613) ELECIRIC FIELD

MEASUAEMENLS ACEOSS THE HARANG

DISCONINUIEY (VASA) $\frac{44}{42}$ p HC $\$ 5.25$

CSCL O4A G $3 / 13$

$474-19023$

Unclas

32726

\section{NELSON C.' MAYNARD}

FEBRUARY 1974 
For information concerning availability of this document contact:

Technical Information Division, Code 250

Goddard Space Flight Center

Greenbelt, Maryland 20771

(Telephone 301-982-4488) 
Abstract

The Harang discontinuity, the area separating the positive and negative bay regions in the midnight sector of the auroral zone, is a focal point for changes in behavior of many phenomena. Through this region the electric field rotates through the west from a basically northward field in the positive bay region to a basically southward field in the negative bay region, appearing as a reversal in a single axis measurement. 32 of these reversals have been identified in the OGO-6 data from November and December, 1969. The discontinuity is dynamic in nature, moving southward and steepening its latitudinal profile as magnetic activity is increased. As activity decreases it relaxes poleward and spreads out in latitudinal width. It occurs over several hours of magnetic local time. The boundary in the electric field data is consistent with the reversal of ground magnetic disturbances from a positive to negative bay condition. The discontinuity is present in the electric field data both during substorms and during quiet times and appears to define a pattern on which other effects can occur. 


\section{Introduction}

\section{A. The Harang Discontinuity}

Harang (1946) concluded, from a study of high latitude magnetic disturbances seen at a chain of ground stations in Scandinavia, that a discontinuity exists in the auroral current systems in the pre-midnight region. That paper also suggested that related boundaries might be found in auroral luminosity and auroral motions, effects that were later found by Heppner (1954) and Davis (1962) respective1y. In recognition of this, Heppner (1972a) has recently named this boundary the "Harang discontinuity". The importance of this boundary lies in that it is a region of change for most phenomena associated with substorms and convection. In the following a few of these points will be emphasized (see Heppner (1972a) for more detai1).

Harang's disturbance field patterns clearly show the existence of the overlap in longitude between the positive and negative bay regions in the auroral zone, delineating the Harang discontinuity. The "double wave patterns in $\Delta Z$ " led him to the conclusion of a definite current discontinuity. The position of the discontinuity for moderately disturbed conditions (class III in his Figure 3) lies from about 21 hours local time at $63^{\circ}$ geomagnetic latitude to beyond 19 hours local time at $68^{\circ}$ geomagnetic latitude. Heppner (1972a) pointed out that about 2 hours difference exists between local time and geomagnetic local time in Scandinavia, shifting the boundary as defined by Harang nearer midnight in geomagnetic coordinates. Its lower latitude end would be near 23 hours. Another shift towards midnight results from the averaging nature of ground magnetometers. Since negative bays are usually stronger than positive bays, this biases an average demarcation between them toward the positive region. 
In addition to the reversal of ionospheric currents from eastward Hall currents to westward Hall currents and their resultant reversal of the $\Delta H$ component of $\vec{B}$, a number of other parameters change at this boundary. Auroral luminosity, brightest just to the morning side of the boundary, changes character from homogeneous quiet arcs in the evening to active, brilliant rayed structures and diffuse aurora in the morning hours. Heppner (1954) found this transition to coincide with the magnetic $\Delta \mathrm{H}$ reversal. Davis (1962) identified a corresponding boundary, again coincident with the $\Delta H$ reversal, where the motions of auroral forms reversed. His studies showed a westward motion on the evening side and an eastward motion on the morning side. Motion at the boundary in his figures shows some southward tendencies, but all directions can be found. Davis's average alignments of auroral forms in both the auroral and polar cap regions form a typical two cell convection pattern (first proposed by Axford and Hines, 1961), implying that convection is a dominant mechanism in both motion and alignment of auroral forms.

Convective patterns have also been established by numerous electric field measurements both with barium ion clouds and double probe measurements (see reviews of Cauffman and Gurnett, 1972, and Maynard, 1972). The electric field has been established to be basically northward in the evening and basically southward in the morning, the change taking place across the midnight region. A reversal is also seen as one passes from the auroral zone into the polar cap region where convection is"antisunward"as opposed to the "sunward" convection in the auroral region (see Heppner, 1972b (OGO-6), 
and Cauffman and Gurnett, 1971 (INJUN-5)). Auroral zone convective motions are consistent with the motions of auroral forms mentioned in the previous paragraph.

This 1 ist of ionospheric effects covers only the major items, items that are easily observable and are basically substorm oriented. Harang (1946) also recognized that for current continuity in this region one must not look to the polar cap or to lower latitudes, but to field aligned Birkeland currents. Recent ly Heppner et al. (1971) have proposed that in the region of the Harang discontinuity a sheet of net outflow of current exists. The field lines at the discontinuity map into the magnetosphere somewhere in the midnight region of the tail. Lezniak and Winckler (1970) have seen a "fault line" in this region at synchronous altitude in the particle data during substorms. West of their line inflation of the geomagnetic field was occurring while east of it collapse was observed. Inward convection and energization of magnetotail plasma particles was observed in this region of collapse. During substorms DeForest and McIlwain (1971) have also seen this inward convection, with a sharp spatial boundary in the electrons and the protons drifting to the west of the boundary. Many plasma sheet effects have been reported on from this region and in the more distant equatorial plane which are beyond the scope of the material presented here. The pertinent fact is that the Harang discontinuity maps into this region; hence, some of these effects are intertwined with the dynamics of the discontinuity.

In considering average behavior, one must not forget that this is an active dynamic boundary. The movie analysis of $\Delta^{H}$ by Heppner (1967) showed that the boundary actively varies, but with no strong correlation 
of position to disturbance level. The object of this study is to investigate the characteristics of the Harang discontinuity, both active and average, as expressed through the electric field configuration.

\section{B. Electric Field Configuration}

Electric field measurements from OGO-6 (Heppner, 1972b, c) and from INJUN-5 (Cauffman and Gurnett, 1971) have been useful in defining the basic boundaries of the auroral and polar cap zones in most regions with data through the midnight sector being sparse. In Figure 1 the heavy lines are, except for the midnight region, those defined by Heppner (1972b) for moderately disturbed periods. The boundaries have been completed through the midnight sect or from data presented in this paper. The two views in Figure 1 represent schematically a basic convection pattern and the associated electric field in the nighttime region. No attempt was made to fill in the dayside arrows or to accurately relate arrow length to typical magnitudes. Note that the pictures shown imply uniform convection across the polar cap. Other configurations could be drawn representing the pattern being tilted to one side or the other which has been shown to result from different azimuthal directions of the interplanetary magnetic field (Heppner, 1972d), but this would only modify details in the following.

If a satellite was to traverse the midnight region and cross the Harang discontinuity from south to north the following sequence of events might be expected (see Figure 1).

1. The field would gradually increase as the auroral zone is entered and would be basically northward. 
2. At the discontinuity, which may be sharp or broad, the field would rotate through the west toward the south.

3. The field would remain basically southward through the westward electrojet, or negative bay, region.

4. The field would again rotate as the polar cap is entered with the amount of rotation being less and dependent on the actual flow configuration in the polar cap.

The field configuration across the discontinuity may be quite variable, in particular in the east-west component due to eddy motions etc. (see Heppner 1972a). In a single axis, basically north-south, satellite measurement of electric fields one would expect a reversal of the field followed by some kind of change on entering the polar cap.

The most illustrative, previously published electric field measurements in the Harang discontinuity region are the barium release measurements of Wescott, et a1., (1969) from Norway. Just prior to passing through the discontinuity, convective motions were westward (northward field). As $\Delta \overrightarrow{\mathrm{H}}$ reversed, motions toward the south were observed (westward field), with eastward motions (southward field) dominating as $|\Delta \mathrm{H}|$ increased (see also Heppner, 1972a). Recently Banks et al. (1973) have measured electric fields through the midnight region using the incoherent backscatter radar at Chatanika, Alaska. Measuring only one component on a given night they find that the north-south component reverses to south as $\Delta \vec{H}$ reverses; and, when they observe the east-west component, they find an enhancement of the westward field at the discontinuity, consistent with the above picture. 
II. Measurement and Data Handling Techniques

\section{A. Spacecraft and attitude considerations}

The electric field measurements discussed here are all from the single axis double floating probe experiment on the polar orbiting 0GO-6 (see Maynard and Heppner, 1970; and Heppner 1972 b). Long cylindrical probes deployed from each of the two solar arrays were utilized as the sensors with the distance between the mid points of the active elements being 18.4 meters. A11 measurements here were taken when the satellite was in eclipse, due to a problem with one of the solar arrays which caused saturation of the electronics in sunlight after June, 1969 (see Heppner, 1972b). This data was taken during November and December, 1969, in the northern hemisphere when apogee was at mid and low latitudes on the dayside and moving from south to north. The measurement altitude was between 400 and $1100 \mathrm{~km}$.

The OGO eclipse data presents a special problem to the DC electric field results that is not pertinent to the previous results of Heppner (1972 a, b, c, d; 1973) which were based on measurements made in sunlight prior to the solar array fault. In eclipse the spacecraft still maintains one axis pointing toward the earth, but frees itself to turn about that axis. Thus, in a south to north orbit, by the time the spacecraft has reached the northern auroral zone, the antennas may be in any orientation in a plane parallel to the earth's surface. There was no direct attitude sensing instrument on board for operation in eclipse. To construct a probable attitude, necessary for $\vec{v} \times \vec{B}$ subtraction, the shaft angle of an experiment designed to track the velocity vector was monitored and smoothed. From this a probable direction of the velocity vector was obtained, relative to the 
spacecraft axes, that could be used as a second attitude reference in computing the proper $\overrightarrow{\mathrm{v}} \times \overrightarrow{\mathrm{B}}$ for subtraction from the data.

For some orbits this technique fails to follow the proper motion as evidenced by obvious nonsensical excursions of $\vec{E}=\vec{E}-\vec{v} \times \vec{B}$. Note that the maximum $\vec{v} \times \vec{B}$ is in the order of $360 \mathrm{mV} / \mathrm{m}$; hence, depending on antenna orientation in this field, a $10^{\circ}$ error could change a resultant component of $\vec{E}$ by as much as $60 \mathrm{mv} / \mathrm{m}$ or as little as $5 \mathrm{~m} / \mathrm{vm}$. In other cases the computer solution appears to follow the attitude well and clearly recognizable patterns evolve which will be the subject of this discussion. In all cases slowly varying systematic errors may exist in the $\vec{v} \times \vec{B}$ subtraction. When it is obvious that they do exist, the curves will include a shaded area which is a "best guess" of the additional $\vec{v} \times \vec{B}$ contamination. Criteria for drawing in this shaded area are: (1) does it remove a slowly changing bias from an otherwise recognizable pattern, and (2) is it the minimum that can be smoothly subtracted off to achieve a physical result thus biasing toward the computer solution of the attitude (see Cauffman and Gurnett, 1971, for a similar technique for removal of $\vec{v} \times \vec{B}$ ). In a reversal pattern an error of this type would add to the field on one side of the reversal and subtract from the other side. For this reason, magnitudes will be used in the following only in a qualitative sense, and the accuracy of the location of the reversal will depend on $\mathrm{dE}_{\mathrm{r}} / \mathrm{dt}$, or more correctly in terms of the orbit, $\mathrm{dE}_{\mathrm{r}} / \mathrm{dx}$.

In the following sections the electric field data will be presented linearly in time, with magnetic local time and invariant latitude as noted. A11 polar plots are in a magnetic local time - invariant latitude 
coordinate system. Magnetic observatories are plotted in that system with the disturbance vectors calculated in geomagnetic coordinates and then plotted from the invariant location. A listing of the magnetic observatories used with their abbreviations and geomagnetic and geographic locations is given in Table I. The horizontal disturbance vectors were found using as a baseline the period from 16:00 UT on November 14, 1969, to 06:00 UT on November 15 during which AE(10) was essentially zero. AE (10) is the $\mathrm{AE}$ index calculated with data from 10 of the usual 11 stations (Tixie Bay was missing). $\Sigma \mathrm{K}_{\mathrm{p}}$ for this period was $0+$. Magnetogram tracings are for the $\Delta \overrightarrow{\mathrm{H}}$ component on $1 \mathrm{y}$ and use the same baselines.

\section{B. Data Selection Criteria}

As noted in Section IB, a single axis electric field experiment would see a reversal in the north-south component with the only easily predictable portion of the east-west component being a westward direction at the boundary. A second smaller shift in direction may occur as the polar cap is entered; however, this may or may not be distinguishable in a single axis experiment. Often the measured component will tend toward zero. The Harang reversal, or rotation, of the electric field will occur over a finite $\Delta t$ (and corresponding distance along the orbit) and thus define the "width" of the discontinuity. The fact that the measured field (one component on1y) is near zero over this width should not be taken to necessarily imply near zero electric field in this region. Thus reversals of the electric field were sought in the data and then checked to separate those due to the Harang discontinuity from those due to crossing into the polar cap region. 
TABLE I: GROUND MAGNETOMETER STATIONS USED

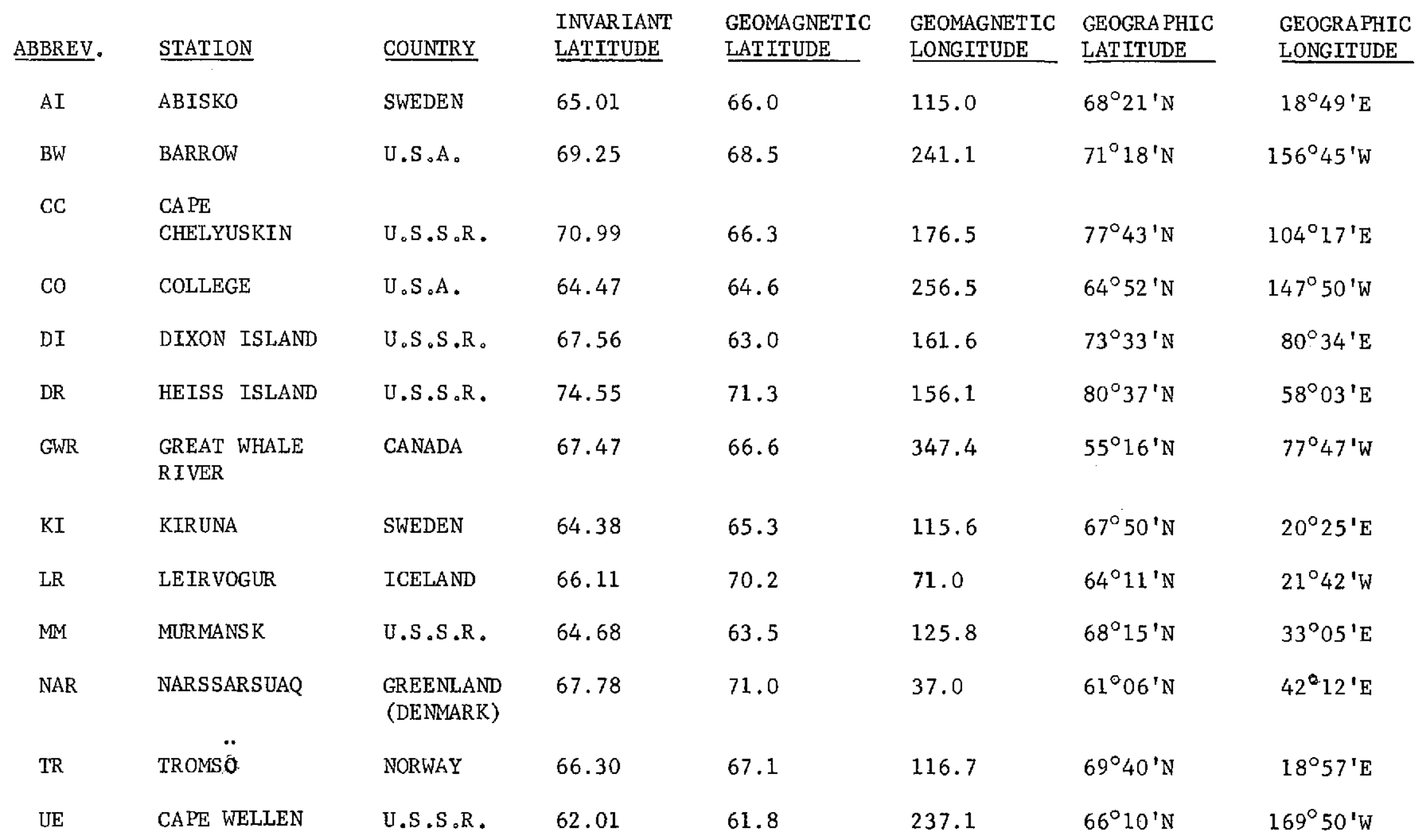


In selecting cases where it is believed that the Harang discontinuity was crossed, the following criteria were followed:

1. All passes were eliminated if the attitude solution resulted in large obvious errors from the $\vec{v} \times \vec{B}$ subtraction.

2. A11 passes in which the measured component was east-west were eliminated as no typical patterns could be found due to generally smaller magnitudes coupled with the attitude problems.

3. A reversal was looked for in the component of electric field that was measured. In order to distinguish Harang boundary crossings from polar cap boundary crossings, the east-west component on the poleward side of the reversal that could be inferred from the measurement was calculated. If the latitude of the reversal was greater than $65^{\circ}$, and if that calculated component was greater than about $20 \mathrm{mV} / \mathrm{m}$ or less than $80 \mathrm{mV} / \mathrm{m}$ westward (corresponding to antisunward convection across the polar cap), the crossing was thrown out as being questionable. This criteria in general threw out cases in which the antennas were oriented in a north-east to south-west direction.

The above criteria and data gaps limited the number of identifiable crossings of the Harang discontinuity during the eclipse season of November and December, 1969, to 32. In no case, however, did the opposite conditions apply: i.e. cases did not occur where we could unequivocably say that no boundary existed when at the magnetic local time and invariant latitude where a crossing would be expected. 
III. Measurement Results

B. Low Magnetic Activity

A basic question that occurs about the Harang discontinuity is: "Is the discontinuity related to substorms only or does it exist all the time"? Figure 2 presents data taken near 01:50 UT on November 22, 1969, that indicates that the discontinuity is present during quiet times. This pass occurred on a quiet day when $\mathrm{AE}(10)$ was approximately zero and only one significant substorm had occurred during the previous day and a half, that being almost nine hours previous. The right panel of Figure 2 shows that at the time of the pass (denoted by A) the horizontal $\vec{\Delta}$ was near zero at the observatories at Tromsö, Leirvogur, Narrsarrsuaq and Great Whale River. The location of these stations, the orbit track, the direction of the antenna axis and the location of the discontinuity are shown in the polar plot at the top of Figure 2. Note also that the small substorm that is seen in the Narrsarrsuaq magnetogram is still $1 \frac{1}{2}$ hours away. The electric fields observed (lower left, Figure 2) are large with the total change from peak positive to peak negative being over $130 \mathrm{mV} / \mathrm{m}$. The discontinuity, located near $73^{\circ}$ INV. LAT., is denoted by the heavy black bar. The shaded area under the curve should be visually removed from the data as explained in section IIA. Note that the direction of measurement is tipped toward the northeast (see section IIB). If all of this negative magnitude of about $85 \mathrm{mV} / \mathrm{m}$ were from a dawn-dusk field, that field would have to be over $170 \mathrm{mV} / \mathrm{m}$ which is definitely not a typical polar cap field (see Heppner 1972b). Thus this case was judged to be a Harang crossing in which the polar cap was 
probably entered near $77^{\circ} \mathrm{INV}$. LAT. The lack of magnetic variations coupled with the large electric field again points out that the conductivity must be known to relate magnetic variations to electric fields (Wescott, et a1., 1969).

A slightly more active condition is illustrated in the data from December 8,1969 , between 15 and 20 hours UT. The ground magnetic disturbance data is shown in Figure 3 . A small substorm was commencing at the time of the first pass (denoted by A) as evidenced in the magnetograms from Heiss Island and Cape Chelyuskin. This later grew in magnitude as Dixon Island passed under the discontinuity showing a negative $\Delta H$. Pass $B$ was after most of the activity had ceased with Dixon Island again showing a positive $\Delta H$, while pass $C$ was just prior to the onset of a second bay seen at Tromsö.

The corresponding electric field data are shown in Figure 4. In all three cases the electric field was much smaller than that observed on November 22. The direction of the measured component is shown in the polar plots to the right. In case A the Harang boundary was not conclusive (hence, it was not included as a definite boundary) due in part to the small electric field magnitude, making it difficult to check the $\vec{v} \times \vec{B}$ subtraction. It is possible that the field may reverse somewhere between 70 and $73^{\circ}$ INV. LAT. if the $\vec{v} \times \vec{B}$ subtractions were adjusted. The horizontal magnetic disturbance vectors plotted in the right panel of Figure 3 would seem to indicate that the discontinuity should be between Dixon Island and Cape Chelyuskin. Between the first two passes the magnetic records indicate the boundary should have moved south of Dixon Island 
and then returned north again. The second pass shows a clear reversal occurring near $72^{\circ}$ INV. LAT. which would project between Dixon Island and Cape Chelyuskin in harmony with the magnetic data. The abbreviated third pass shows that the discontinuity has started to move southward as activity is building toward the bay commencing about $\frac{1}{2}$ hour later at Tromsö. The location of the boundary in these cases is at high latitudes, consistent with the low level of substorm activity, $\mathrm{AE}(10)$ being 100 or less for these passes.

\section{B. High Magnetic Activity}

At higher levels of magnetic activity the discontinuity is located further south. Figure 5 shows electric field data (including the direction of the measurement) from three passes on November 7, 1969. The $\Delta \vec{H}$ magnetometer records corresponding to these times are found in Figure 6 . The first pass (near 10:20 UT and denoted by A in Figure 6) occurred after a weak disturbance at College and to the east. The Harang discontinuity is seen to be somewhat spread out between 64.5 and $66.5^{\circ}$ INV. LAT. In this case and in the other two passes here a sharp upper boundary clearly defines the entry into the polar cap. The magnetic disturbance vectors in Figure 6 are small and consistent with the observed discontinuity. College, almost under the noted Haxang location, is showing a small negative $\vec{\Delta}$.

The second pass (near 12:02 UT) occurred just at the onset of the large bay at College. $\mathrm{AE}(10)$ went over $1000 \mathrm{y}$ at the height of this bay and was $500 y$ at the time of the pass (indicating significant activity to the east of College already in progress at this time). The electric field reversal is much sharper and better defined, being located at about 
$63^{\circ}$ INV. LAT. The lower convection boundary is close to the discontinuity. Cape Wellen, which was to the southeast of the point of contact with the discontinuity, reflects this in its low negative $\Delta \overrightarrow{\mathrm{H}}$. Referring to Figure 1, Wellen would be at a location corresponding to the lower latitude tip of the negative bay region next to the discontinuity.

The third pass (near 13:42 UT) occurred after recovery from the bay in a "positive overshoot" with all stations being near zero or slight ly positive. It is clear that a reversal associated with the discontinuity still exists; however, it would appear, with the proper baseline adjustment for $\vec{v} \times \vec{B}$ errors, that it may be spread out between $64^{\circ}$ and $73^{\circ}$ INV. LAT. The upper or polar cap boundary has moved up near $76^{\circ}$ INV. LAT. Thus with decreasing activity the discontinuity has shifted northward and spread out.

Another serles of active examples is presented in the data from November 30, 1969. The electric field data is presented in Figure 7 while the ground magnetic disturbance data is shown in Figure 8 . Also available at this time are scanning photometer records of the $5577 \AA$ green line from the Kiruna Geophysical Observatory. These are presented in Figure 9 and a $3-D$ format with horizontal range, universal time and intensity being the axes. As Kiruna rotates with the earth in time (see the location of Kiruna at the times of interest in Figure 8), the location and intensity of the auroral luminosity varies resulting in the observed structure. No attempt has been made to correct for the fact that closer to the horizon one is looking through more auroral forms due to their vertica1 extent. 
The first pass (denoted by $A$ in Figure 8 , top panel of Figure 7 and occurring just before the data presented in Figure 9) was into the latter stages of a large bay seen as a negative $\vec{H}$ at Cape Chelyuskin, Dixon Island and Murmansk. The Harang discontinuity reversal is seen to be between 60 to $62^{\circ}$ INV. LAT. while the transition into the polar cap is very mixed up, possibly due to the angle of the measurement. Note that in this case the discontinuity is at a very low latitude and over $1 \frac{1}{2}$ hours prior to magnetic midnight, illustrative of the range of local times over which it can be found. The direction of the measured component is north-east; however, the low latitude precluded this from being a polar cap reversal (see section IIB). $A E(10)$ in this case was 500 . The overlap of the negative and positive bay regions appears to extend significant ly to the west as the Murmansk $\Delta \vec{H}$ is just slightly negative (probably from higher westward currents to the north) and the Tromsö disturbance vector is basically westward. The photometer data beginning about 8 minutes later shows most of the auroral activity occurring to the north of Kiruna and much of it somewhat north of Tromsö (about $200 \mathrm{~km}$ north of Kiruna).

In the second pass (denoted as B in Figures 8 and 9 and the second panel in Figure 7) activity has decreased from the previous case, and we are just prior to the beginning of another bay. $A E(10)$ has dropped to about 300 . Here we see a spread out boundary in latitudinal width (from about $63^{\circ}$ to $68^{\circ}$ INV. LAT.). The auroral activity after having increased has settled down to a few kilorayleighs north of Tromsö. The discontinuity also appears to be located to the north of Tromsö.

The auroral activity increased significantly at the onset of the next bay at Tromsö and moved well south of Kiruna. However, by the time 
of the third pass (C) there was little aurora to be found north or south of Kiruna. The component of electric field being measured in the third pass is nearer east-west and the magnitudes are small. This was not considered a definite Harang type pattern but is included for continuity during this period and as an example of a more "east-west" type pattern. While nothing definite can be said of the exact location of the discontinuity with respect to the aurora from these passes, it is clear that the brightest aurora in the late evening sector, where overlap of the positive and negative region exists, is probably in the vicinity of the Harang discontinuity. It also extends southward of the region of the discontinuity. Information as to the northward extent is lacking; however in the period between $B$ and $C$ where Abisko went strongly negative there was still strong aurora to the north. These observations are consistent with the previous studies of Heppner (1954) and Davis (1962). IV. Discussion

In the previous section several cases have been presented showing crossings of the Harang Discontinuity at varying levels of magnetic activity. A summary of all measured locations is shown in Figure 10. The crossings are categorized according to the related value of $\mathrm{AE}(10)$, and plotted with the length of the line determined by the width along the orbit track. Note that, especially for the middle range of $A E$, the location may be almost anywhere over a $12^{\circ}$ latitude range and 3 hour magnetic local time range. Other data seem to indicate that the boundary, at least at high latitudes, may extend at times over to and westward of the 21 hour MLT xange; however, crossings were not completely unambiguous, and were not included. Heppner (1972a) pointed out that considerable longitude is 
covered by the possible locations of the discontinuity. This is strongly confirmed in the present study.

In looking at Figure 10 a clear difference exists between the low activity crossings and the high activity crossings. To explore this, these data have been separated in Figure 11 in a characteristic low activity discontinuity and a high activity discontinuity. Also plotted are the lower convection boundaries, defined as when the electric field first exceeded about $10 \mathrm{mV} / \mathrm{m}$, with the same $\mathrm{AE}(10)$ criteria. The "average" boundary lines that have been drawn in are done so with artistic license. Note the large shift in latitude with magnetic activity, and also that the slope of the latitude-magnetic local time profile steepens with increasing activity. Thus as activity increases, the eastern end of the discontinuity moves further southward than the western end.

This raises the question of what is happening in the magnetotail corresponding to this. Figure 12 shows two projections of these boundaries into the equatorial plane. The left plot involves just the dipole conversion between invariant latitude and $L$ resulting in an $L$ versus magnetic local time plot. In the right plot the model of Mead and Fairfield (1974) has been used. Note that beyond $10 R_{e}$ the Harang boundary projects to a distance above the equatorial plane; thus the quiet Harang boundary in fact extends nearly straight back into the tail. The implications as substorm activity increases are:

1. convection boundaries move further inward

2. a larger region is convected toward the morning side resulting in the fault line or place where convection divides being moved toward the dusk side. 
3. a resulting motion of the boundary toward earlier local times is also seen for the inward portion.

Note that beyond some point in the near tail this boundary may not have any meaning in that all convection there is basically sunward resulting from the crosstail field. In closer, relating the fault line of Lezniak and Winckler (1970) to this boundary would seen plausible. They see strong inward convection at, or slightly to the morning side of, this fault line, which is suggestive of the average inward motion observed here with increasing activity. This is also consistent with the westward field predicted across the boundary. Carpenter and Akasofu (1972), by following the inward motion of whistler ducts, have ohserved enhancements in the westward electric field in the midnight region of the equatorial plane near the plasmapause at the time of auroral expansion. On the evening side Williams et al. (1974) have deduced from particle data from Explower 45 a small radially outward field in the region of $5 R_{e}$ during substorms. Projecting this to the ionosphere, the result is consistent with the northward fields measured in the positive bay region and helps to establish in the equatorial plane the split of the sinward convection in the midnight region, forming a fault line or discontinuity.

The lower convection boundary and location of the Harang discontinuity for disturbed conditions shown in Figure 11 have been combined with the boindaries obtained by Heppier (19720) for $\mathrm{Kp} \approx 3$ to generate the overal1 pattern found in Figure 1. The auroral zone-polar cap boundary near magnetic midnight lacked enough definite crossings to adequately define it, so it is put in as a dashed rather than solid line. 
The dynamical nature of the Harang boundary is the most apparent feature observed as one studies the data. This is illustrated in the examples from November 7 shown in Figures 5 and 6 . As noted in section IIIB the boundary sharpened and moved southward as the substorm activity increased and then spread out over about 9 degrees in latitude in the positive overshoot recovery from the storm. Corotation effects will tend to assist the relaxation of the boundary in moving it toward morning hours, adding to the poleward motions as activity quiets. The spreading out would indicate a lack of a dominant driving mechanism, allowing disorder to creep in. Heppner (1972a) stated that jumps of 2 or 3 hours MLT in position of the discontinuity must be very rare. This is borne out by the present study in that while smaller motions may occur quickly, the more gross motions seem to develop over several orbits. However, it appears that the position in local time varies enough that a quantitative relationship with activity can not be developed. It is interesting to speculate that the "westward travelling surge" seen at breakup may be a natural consequence of an inward or equatorward displacement of the discontinuity as activity increases. Banks et a1. (1973) see the enhancement of the westward component, consistent with inward convective motion, at the time of the surge.

In quiet cases the boundary may either be spread out or be relatively sharp as was the case in Figure 2. The flatness of the "average" quiet boundary (see Figure 11) is a result of the lower convection boundary being at high invariant latitudes (hence high $L$ values) where $L$ changes rapidly over a short distance. In, a small substorm, occurring only at 
high latitudes (for instance, the "contracted oval substorm" of Akasofu et a1. 1973), the width of the boundary would probably appear narrow. In 1ight of the above, though, a two degree width at $72^{\circ}$ covers over $2 \mathrm{~L}$ she11s, while at $62^{\circ}$ it covers only $0.6 \mathrm{~L}$ shells. This difference in dimensions in the equatorial plane is accentuated even more in the MeadFairfleld projection.

The evidence that the discontinuity exists in the electric field when no substorm activity is present as well as during active periods leads to the conclusion that the electric field reversal is always present. The electric field would appear to create a pattern defining where other effects can occur. That this pattern can in turn be affected by these other effects is evidenced by the dynamic nature of the boundary that has been discussed. While the electric field appears to define where the activity can occur, it does not seem to control when.

In studying ground magnetograms, Chen and Rostoker (1973) recent 1y concluded that the Harang discontinuity can be identified by looking for a strong westward horizontal ground magnetic disturbance. While the present study would not argue with this premise, one should note that the existence of the Harang discontinuity at quiet times would be completely missed by this criteria.

v. Conclusions

The following conclusions are either confirmed or suggested by the data as discussed in the previous sections.

1. The Harang discontinuity appears in the electric field data as a reversal of the north-south component in the pre-midnight to midnight region. 
2. The discontinuity is dynamic in nature and not predictable in a quantitative sense in space and time. It is seen over several hours in magnetic Local time.

3. The discontinuity is present both during substorms and during quiet times.

4. In an average sense, as activity increases the boundary moves to lower latitudes and steepens its latitudinal profile. As activity decreases it relaxes poleward, spreading out in width and tending to corotate.

5. The width of the boundary seems in general to be directly related to this magnetic activity, with the width narrowing as activity increases.

6. The location of the discontinuity as seen in the electric field data is consistent with the reversal of the $\Delta \vec{H}$ disturbance from a positive to a negative bay condition.

7. In the case that could be studied, the maximum auroral luminosity occurred in the vicinity of the discontinuity.

8. Within the capabilities of our present knowledge of the magnetic field configuration in the tail, the discontinuity projects into the midnight region of the equatorial plane where it could correspond to Lezniak and Winckler's (1970) fault line. 


\section{Acknow ledgements}

Special thanks are due to co-investigators on OGO-6, Drs. T.L. Aggson. and J.P. Heppner. I am grateful to Dr. Georg Gustaffson of the Kiruna Geophysical Observatory for providing the photometer data and to Mrs. Mary Miller of GSFC for assembling it into the three-dimensional format. Mr. Herb Gillis also provided programing support.

$\mathrm{AE}(10)$ indices and magnetograms were provided through World Data Center A for Solar Terrestrial Physics.

I would also 1ike to thank Drs. J.P. Heppner, M. Sugiura and J.L. Burch for comments on the manuscript. 
REFERENCES

Akasofu, S.-I., P. D. Perreault, F. Yasuhara, and C.-I. Meng, Auroral substorms and the interplanetary magnetic field, J. Geophys. Res., 78, $7490,1973$.

Axford, W. I. and C. O. Hines, A unifying theory of high-latitude geophysical phenomena and geomagnetic storms, Can. I. Phys., 39, 1433, 1961.

Banks, P. M., J. R. Doupnik, and S.-I. Akasofu, Electric field observations by incoherent scatter radar in the auroral zone, I. Geophys. Res., 78 , $6607,1973$.

Carpenter, D. L., and S.-I. Akasofu, Two substorm studies of relations between westward electric fields in the outer plasmasphere, auroral activity and geomagnetic perturbations, J. Geophys. Res., 77, 6854, 1972. Cauffman, D. P., and D. A. Gurnett, Double-probe measurements of convection electric fields with the INJUN-5 satellite, J. Geophys. Res., 76, 6014, 1971.

Cauffman, D. P. and D. A. Gurnett, Satellite measurements of high latitude convection electric f'ields, Space Sci. Rev., 13, 369, 1972.

Chen, A. J. and G. Rostoker, Aurora-polar currents during periods of moderate magnetospheric activity, submitted to Planet. Space Sci., 1973. Davis, T. N., The morphology of the auroral displays of 1957-1958:

2. Detail analysis of Alaska data and analysis of high latitude data, J. Geophys. Res., 67, 75, 1962.

DeForest, S. E. and C. E. McIlwain, Plasma clouds in the magnetosphere, J. Geophys. Res., 76, 3587, 1971.

Harang, L., The mean field of disturbance of polar geomagnetic storms, Terr. Mag. Atmos. Elec., 51, 353, 1946. 
Heppner, J. P., A study of relationships between the aurora borealis and the geomagnetic disturbances caused by electric currents in the ionosphere, PhD. Thesis, Calif. Inst. of Tech., Pasadena, 1954.

Heppner, J. P., High latitude magnetic disturbances, Aurora and Airglow,

ed. by B. M. McCormac, Reinhold Publ. Co., New York, 75, 1967.

Heppner, J. P., The Harang discontinuity in auroral belt ionospheric

currents, Geophys. Publ. 29, 105, 1972a.

Heppner, J. P., Electric field variations during substorms, Planet. Space Sci., 20, 1475, 1972b.

Heppner, J. P., Electric field in the magnetosphere, in Critical Problems

of Magnetospheric Physics, ed. E. R. Dyer, IUCSIP Secretariat, National. Academy of Sciences, Wash., D.C., 107, 1972 c.

Heppner, J. P., Polar cap electric field distributions related to the interplanetary magnetic field direction, J. Geophys. Res., 77, 4877, 1972 . Heppner, J. P., High latitude electric field and the modulations related to interplanetary magnetic field parameters, Radio Science, 8, 933, 1973. Heppner, J. P., J. D. Stolarik, and E. M. Wescott, Electric field measurements and the identification of currents causing magnetic disturbances in the polar cap. I. Geophys. Res., 76, 6028, 1971.

Lezniak, T.W., and J. R. Winckler, Experimental study of magnetosphexic motions and acceleration of energetic electrons, J. Geophys. Res., 75, $7075,1970$.

Maynard, N. C., Electric fields in the ionosphere and magnetosphere, in Magnetosphere Ionosphere Introduction, ed. K. Folkestad, Universitetsforlaget, Oslo, 155, 1972. 


\section{$-3-$}

Maynard, N. C., and J. P. Heppner, Variations in electric fields from polar orbiting satellites, in Particles and Fields in the Magnetosphere, ed. B. M. McCormac, D. Reidel, Dordrecht, 247, 1970.

Mead, G. W., and D. H. Fairfield, Quantitative magnetospheric models derived from spacecraft magnetometer data, GSFC X-641-73-363, submitted to J. Geophys. Res., 1974.

Wescott, E. M., J. D. Stolarik, and J. P. Heppner, Electric fields in the vicinity of auroral forms from motions of barium vapor releases, J. Geophys. Res., 74, 3469, 1969.

Williams, D. J., J. N. Barfield, and T. A. Fritz, Initial Explorer 45 substorm observations and electric field considerations, submitted to J. Geophys. Res., 1974. 


\section{Page intentionally left blank}


Figure 5: Electric field data for three consecutive passes during an active magnetic period (see Fig. 6) on Nov. 7, 1969. (see Figure 4 caption).

Figure 6: Ground magnetic disturbance data for Nov. 7, 1969, corresponding to the electric field data shown in Fig. 5 (see Figure 3 caption).

Figure 7: Electric field data for three consecutive passes during an active period on Nov. 30, 1969. Magnetic data for this time is given in Fig. 8 and photometer data is show in Fig. 9. (see Fig. 4 caption).

Figure 8: Ground magnetic disturbance data for Nov. 30, 1969, corresponding to the electric field data shown in Fig. 7 and photometer data shown in Fig. 9. (see Fig. 3 caption).

Figure 9: Kiruna Geophysical Observatory scanning photometer data of the $5577 \AA$ green line for the night of Nov. 30, 1969. The running axis is time; hence both temporal and spatial affects are involved in the intensity variations. The times of the passes for which data is shown in Figs. 7 and 8 are noted as $B$ and $C$ in the drawing (the A pass was just prior to the start of the photometer data).

Figure 10: The location of all crossings of the Harang discontinuity that have been cataloged. The vertical length of the time is a measure of the uncertainty of the time of the crossing: i.e., a measure of the width of the boundary.

Figure 11: "Average" boundaries for both quiet and disturbed conditions. Locations are plotted for both the lower convection boundary and the Harang discontinuity for the noted $\mathrm{AE}(10)$ conditions. 
Figure 12: The projection of the Figure Il boundaries into the equatorial plane using both a dipole I projection and the recent Mead-Fairfield (1974) model. Note that the bottom part of the Mead-Fairfield projection must be visually rotated $90^{\circ}$ as it is the distance above the equatorial plane at $10 R_{e}$ that is given. The quiet and disturbed Mead-Fairfield models were used for the respective boundaries. 

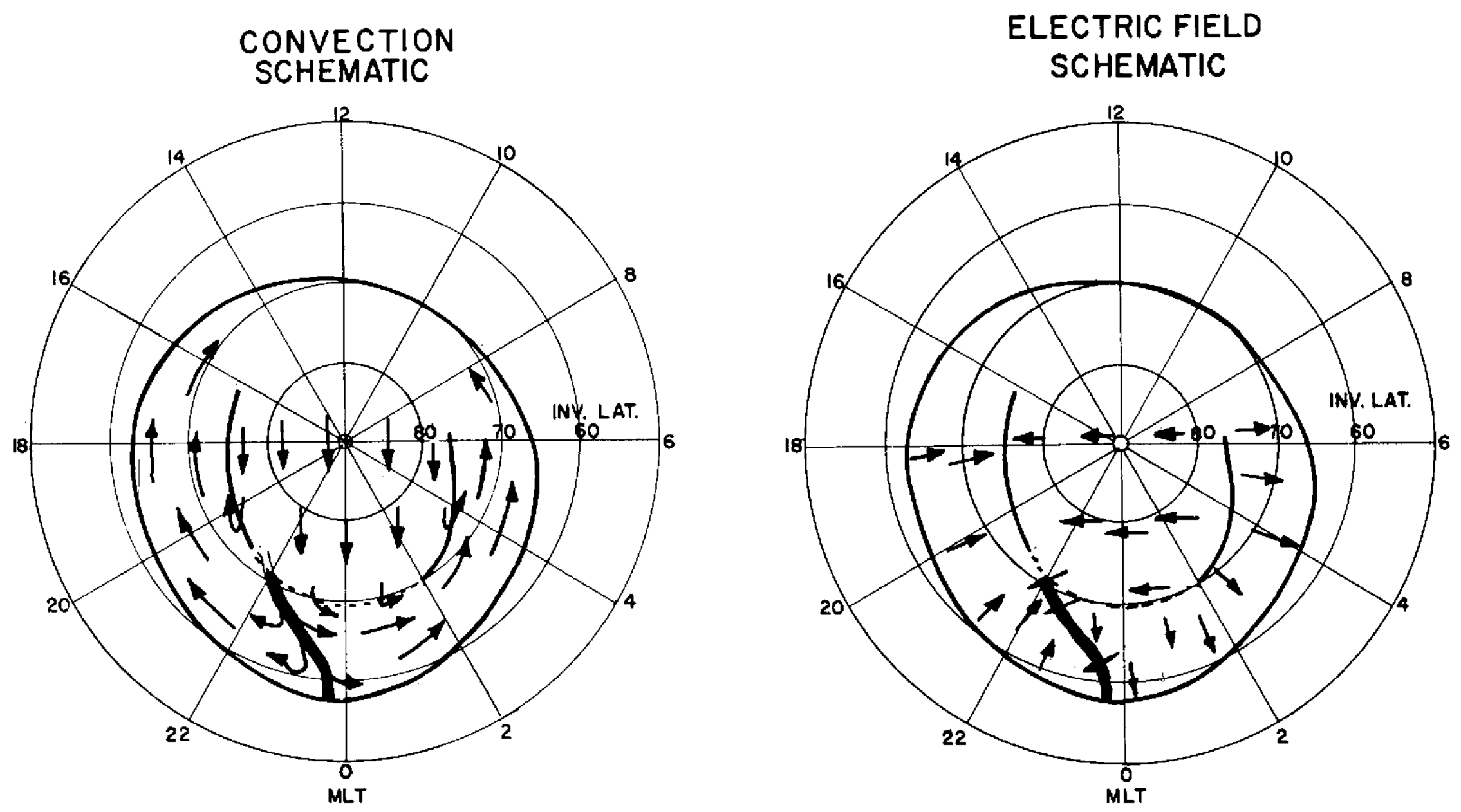

Figure I 

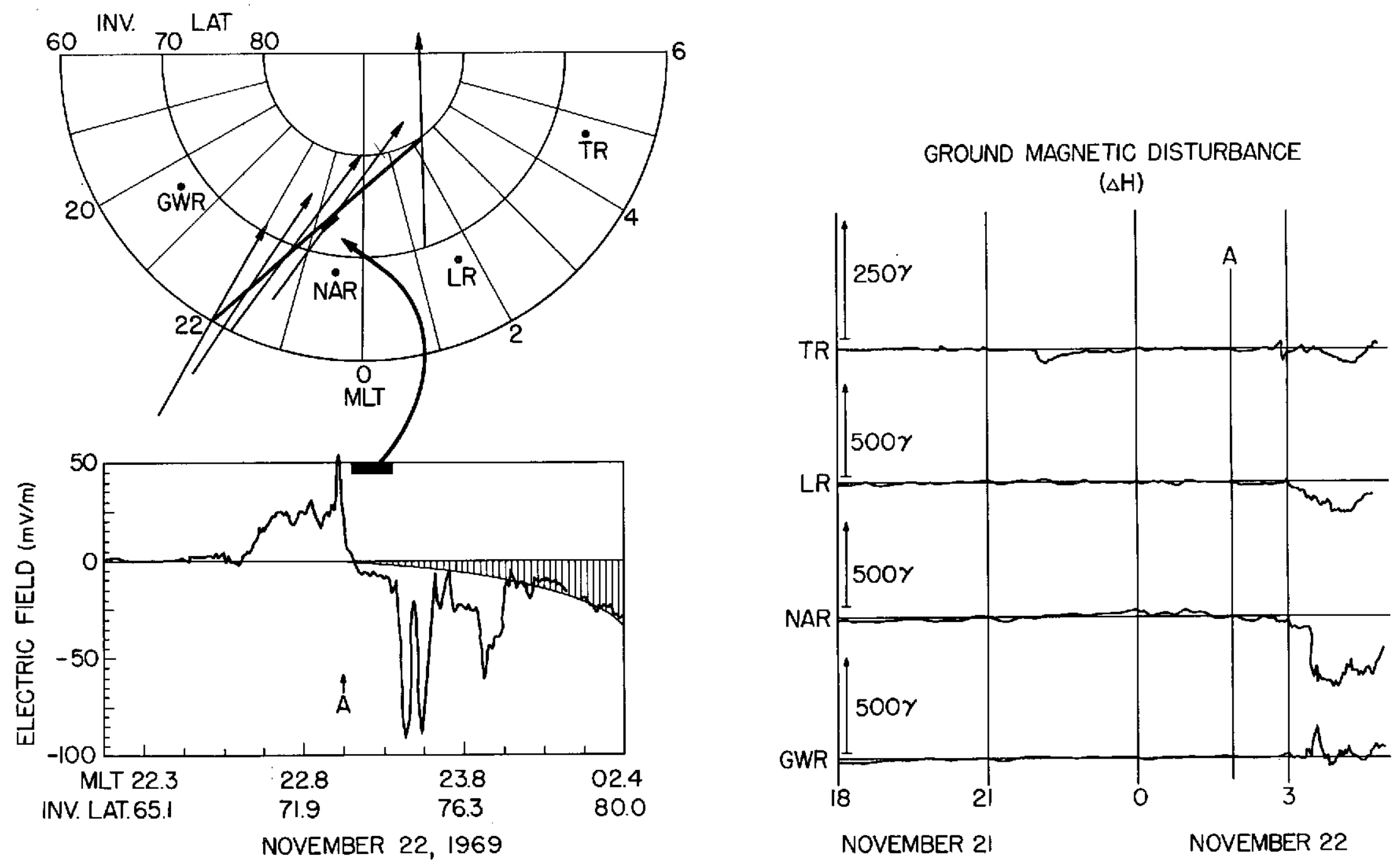

Figure ? 


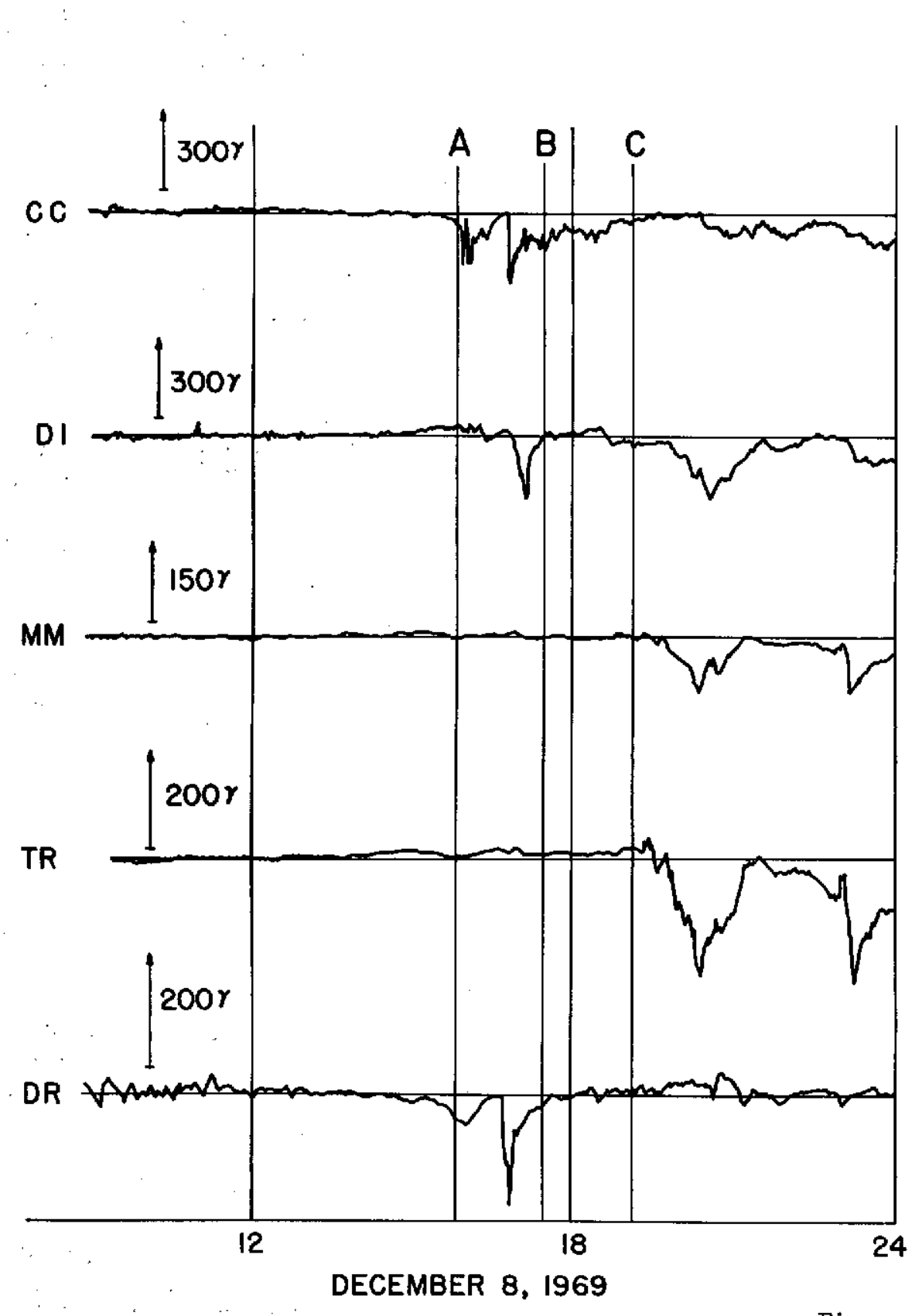

Figure 3

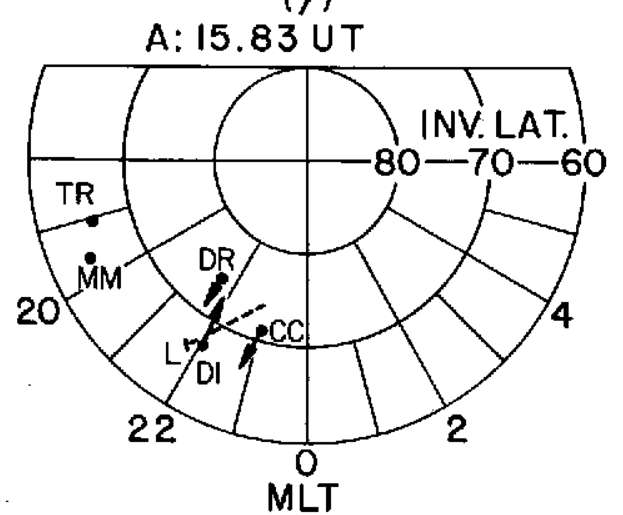

B: $17: 49$ UT
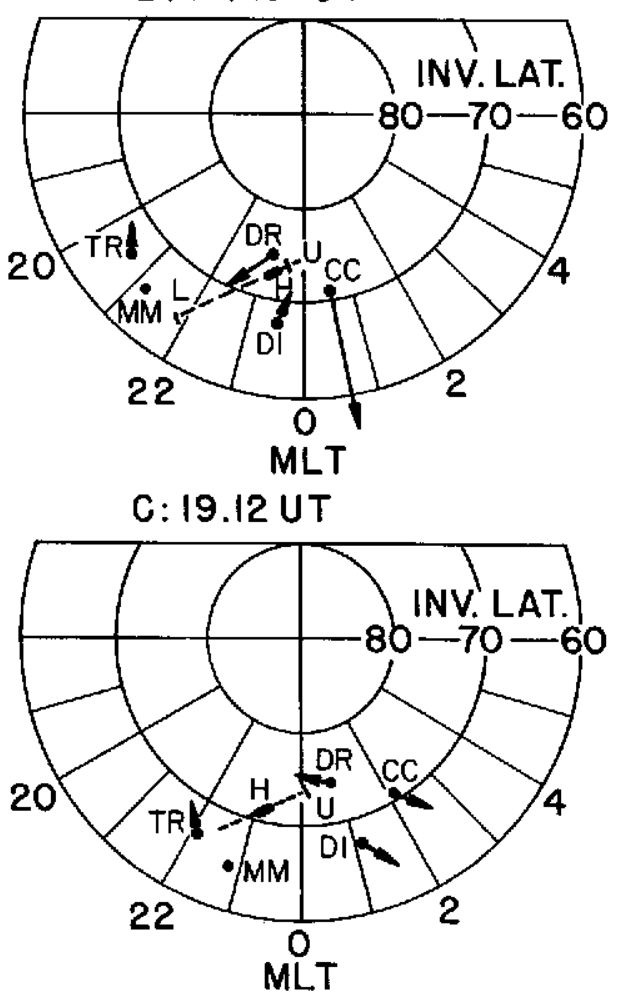

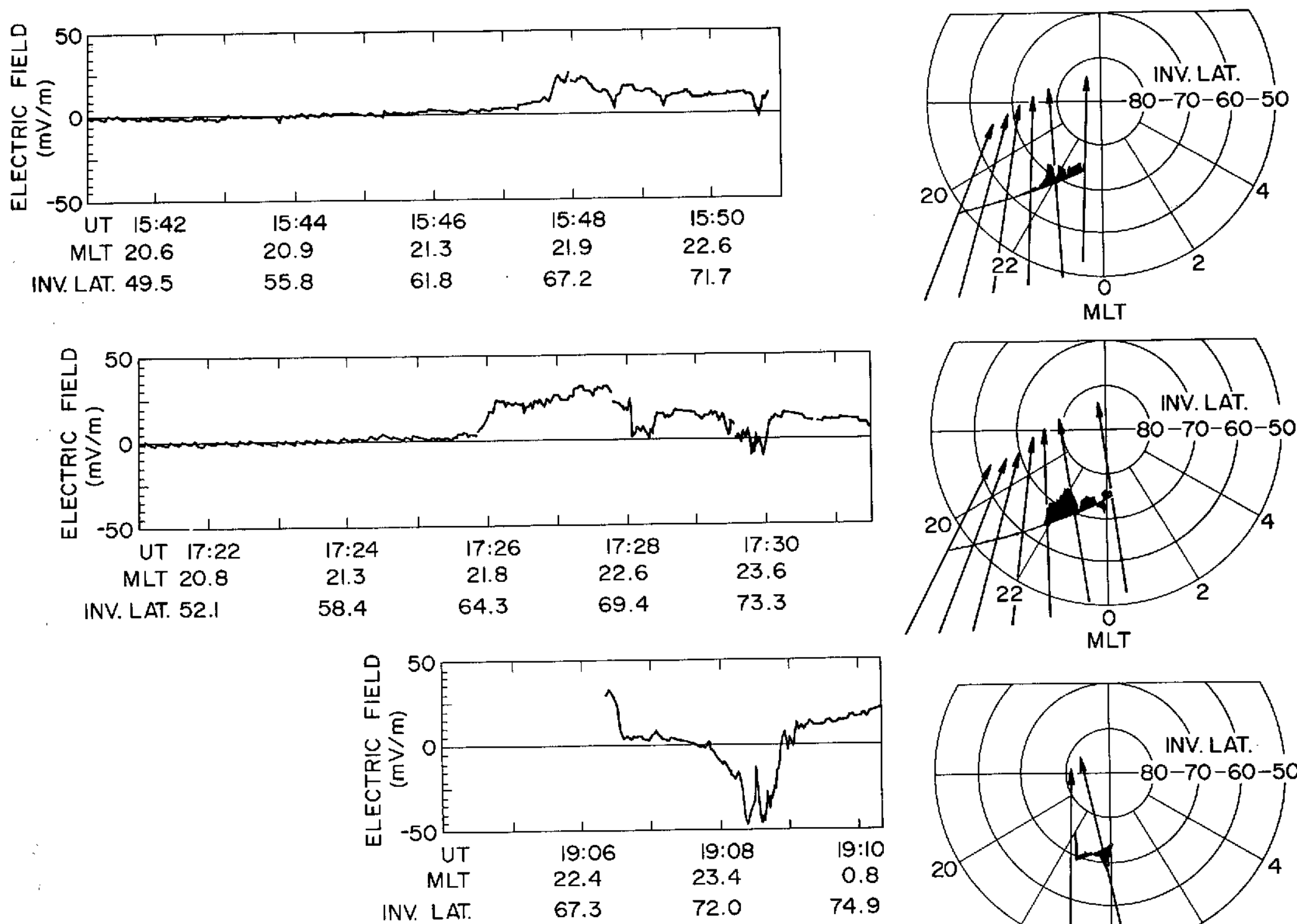

OGO-6 DECEMBER 8,1969
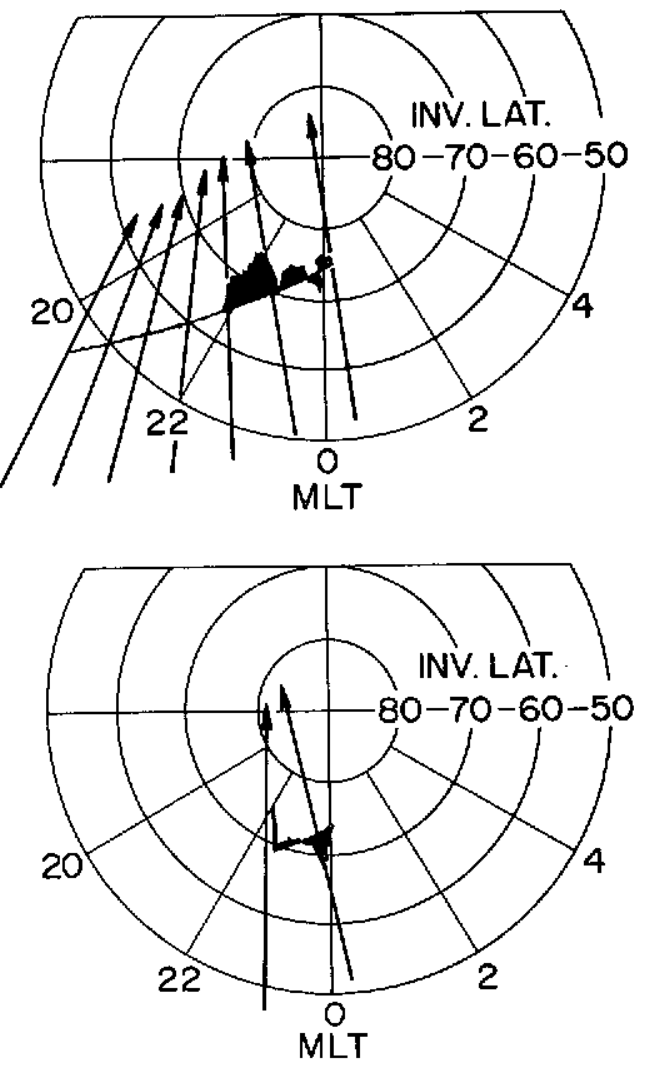

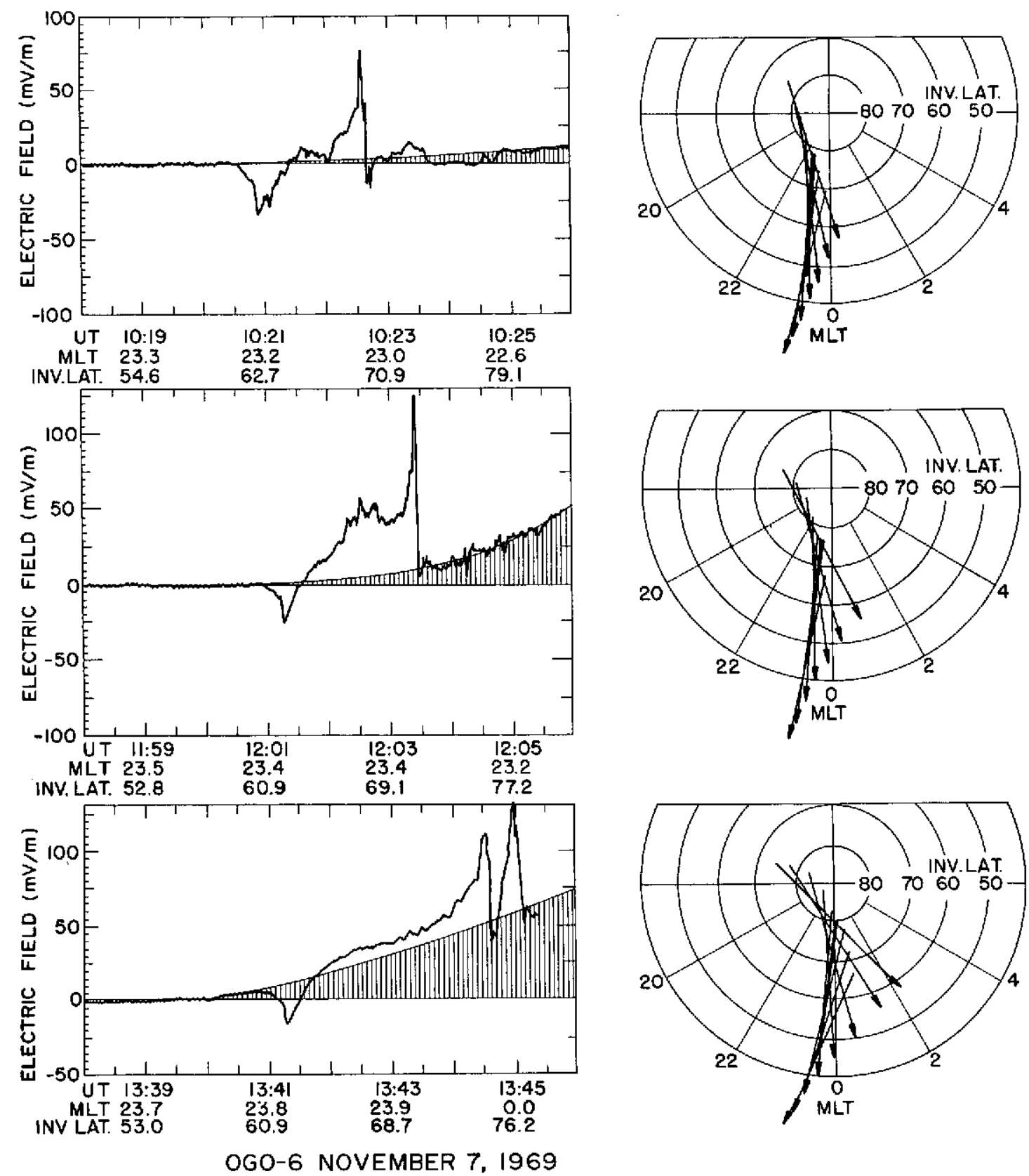

Figure 5 
NOVEMBER 7, 1969
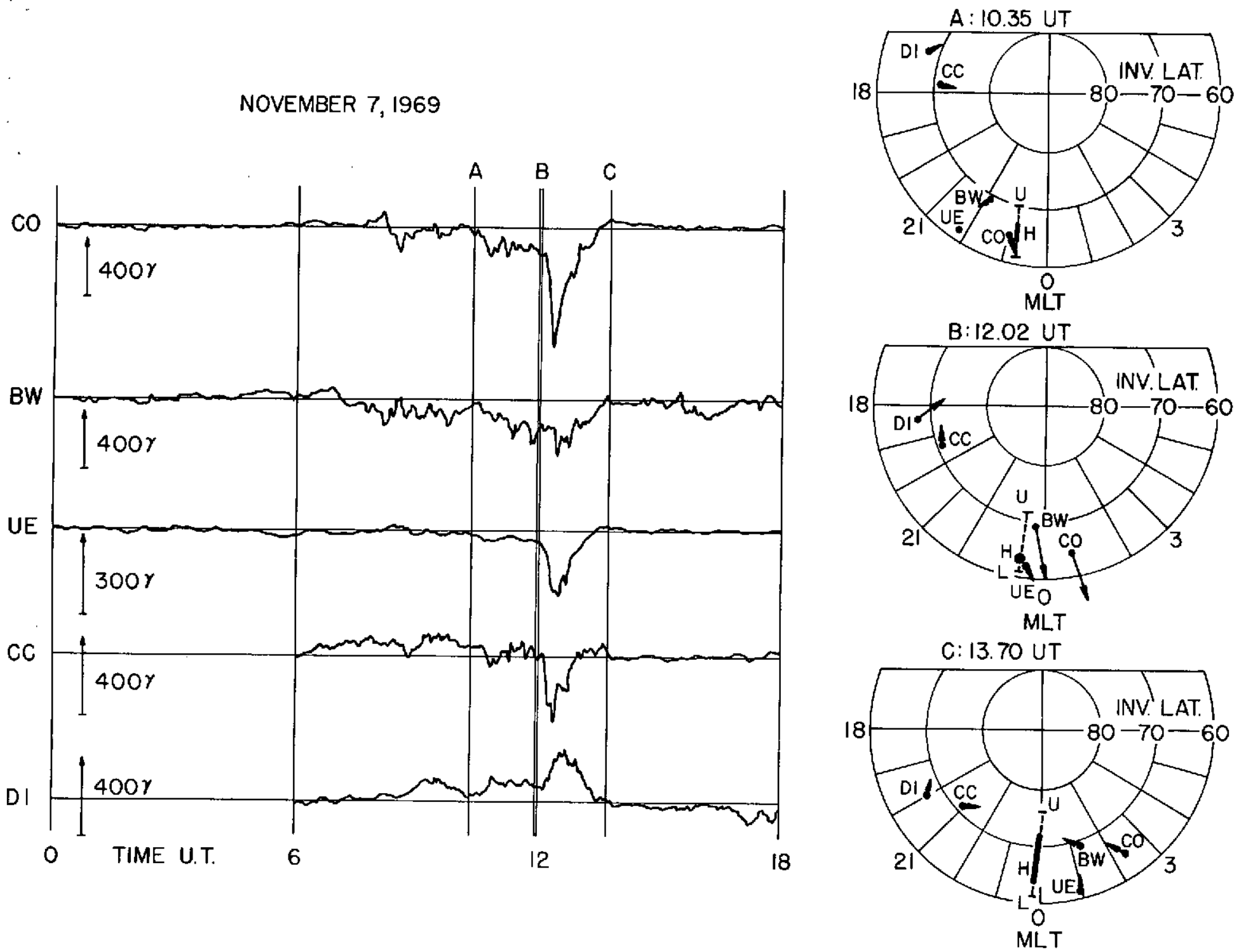

$0 \quad 200$

HORIZONTAL

DISTURBANCE

Figure 6

(r) 
OGO-6 NOVEMBER 30,1969
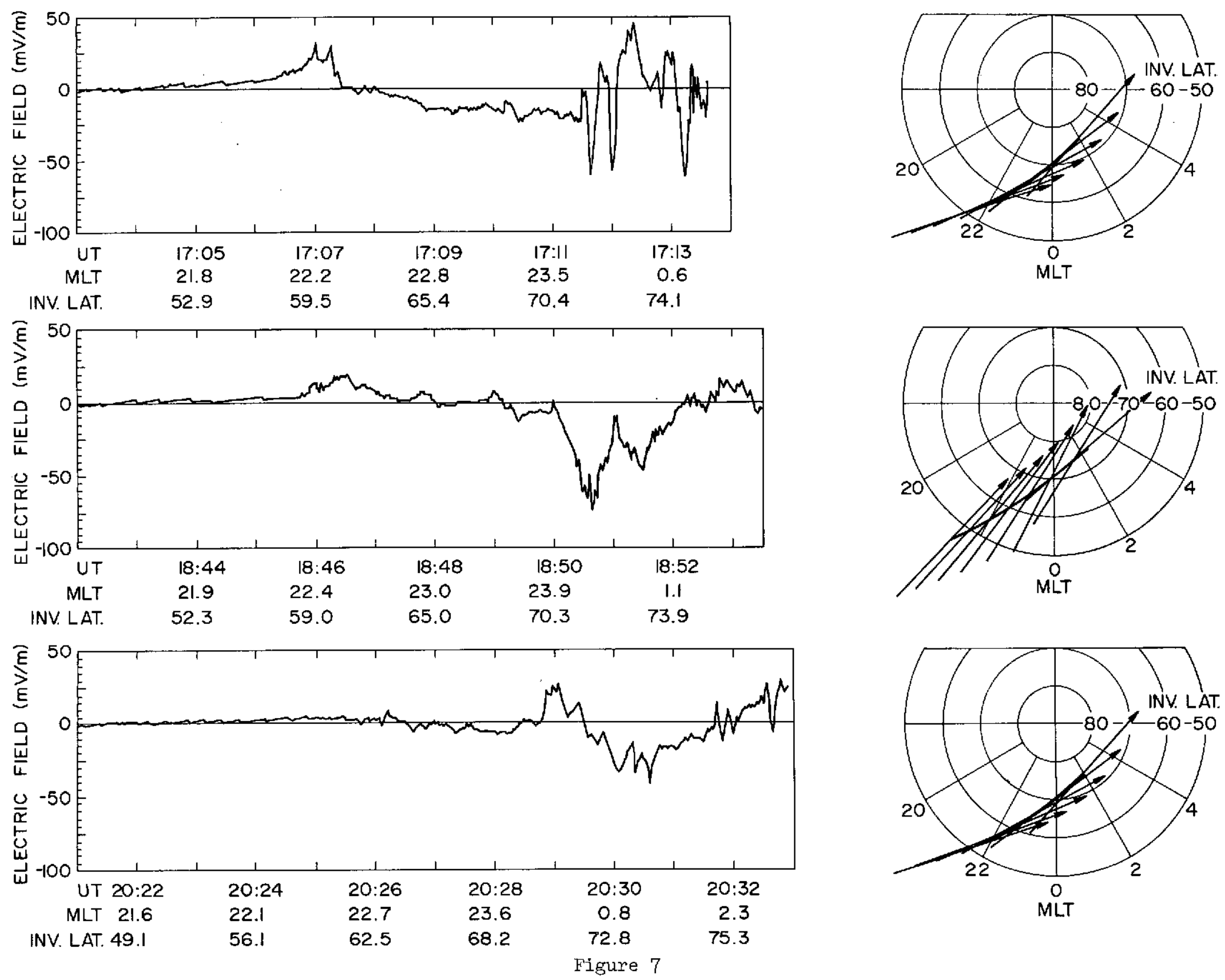

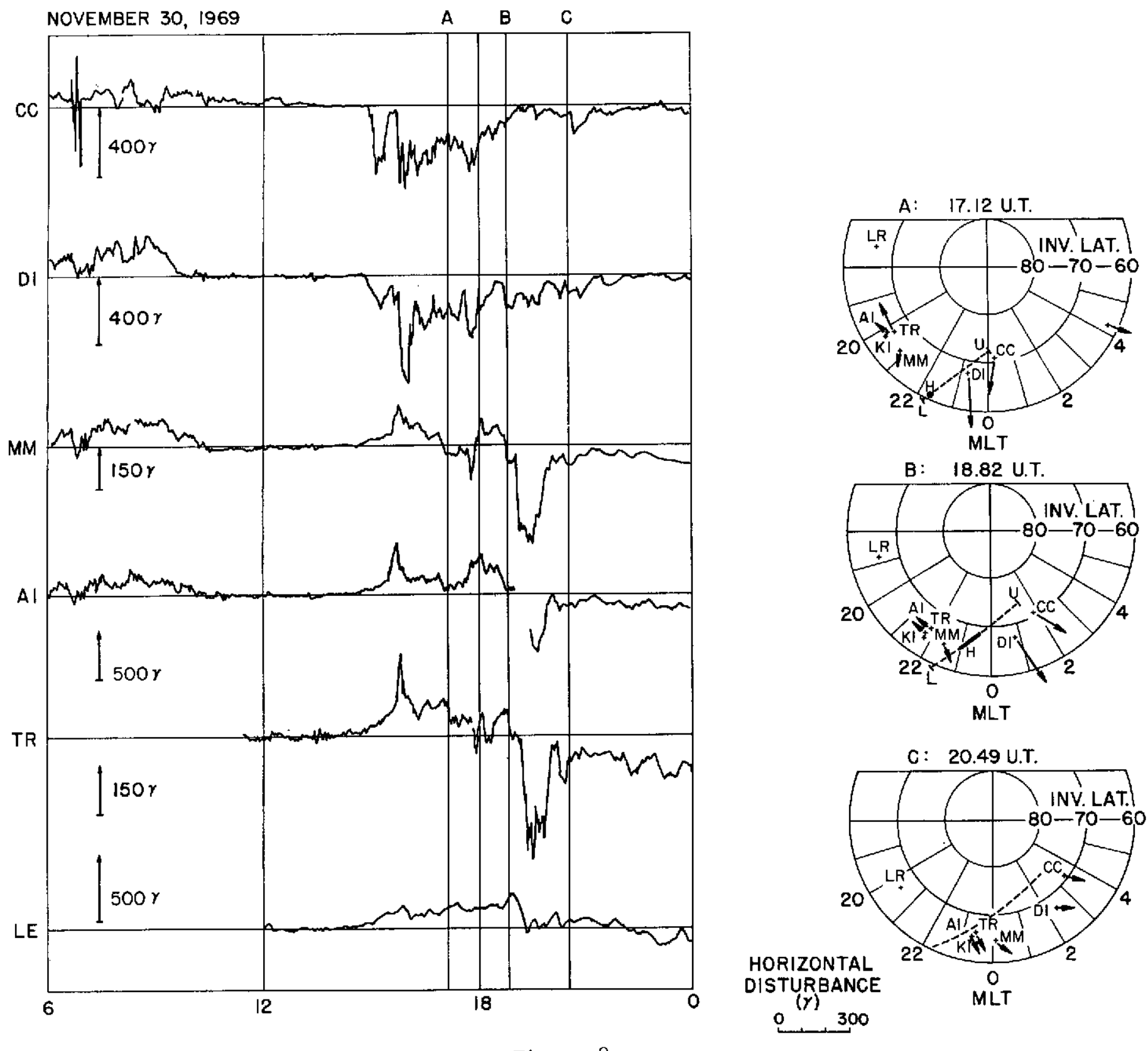

HORIZONTAL DISTURBANCE 0 300

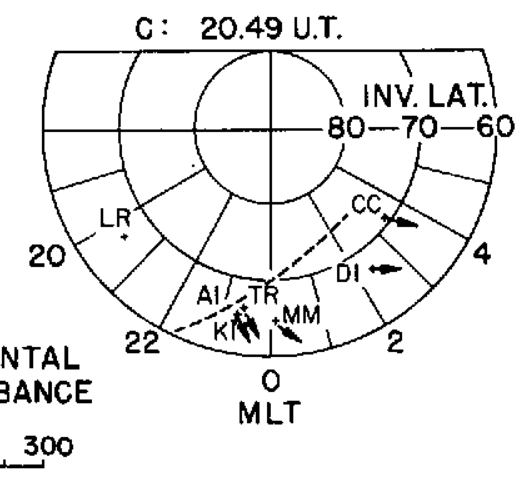

Figure 8 


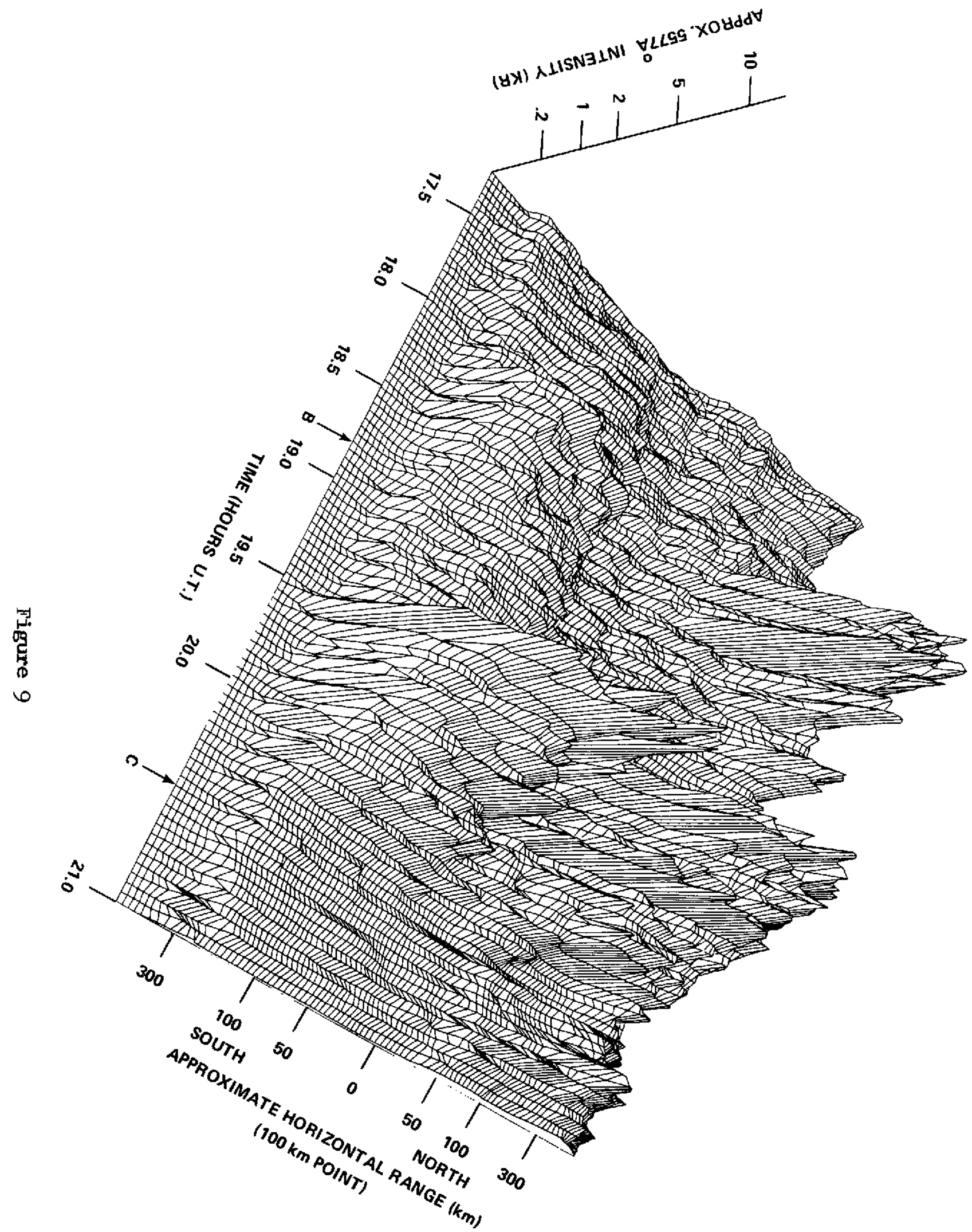


OGO-6 OBSERVATIONS OF THE HARANG DISCONTINUITY

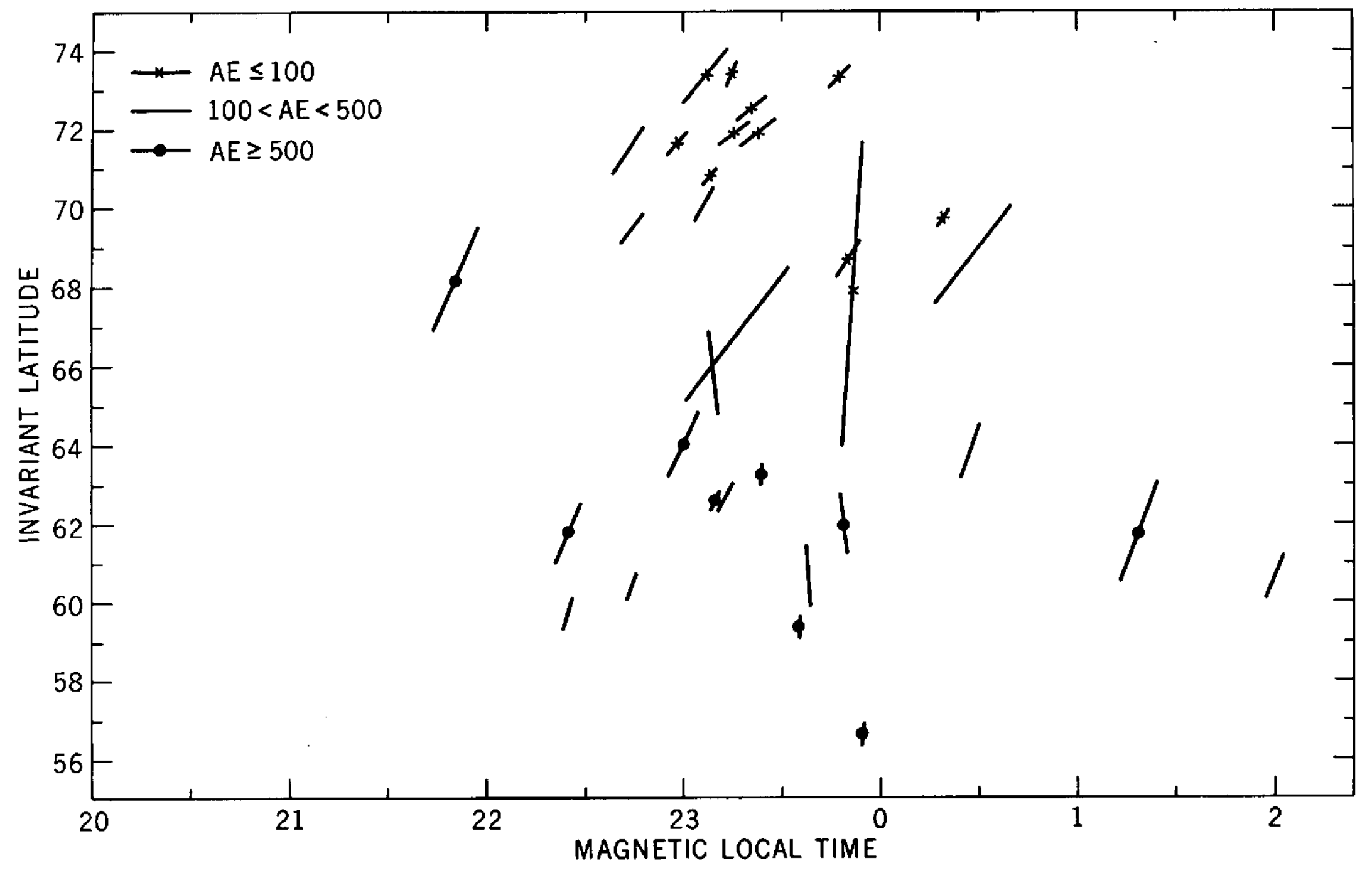

Figure 10 
OG0.6 QUIET HARANG

ELECTRIC FIELD REVERSALS

$\mathrm{AE} \leq 100$

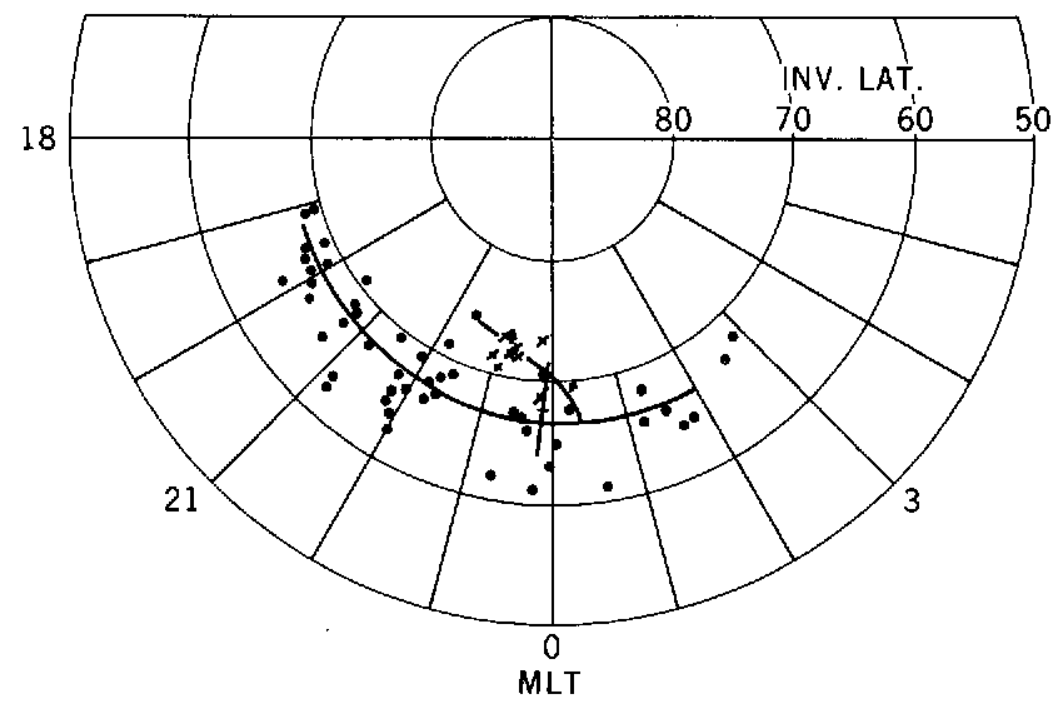

OGO-6 DISTURBED HARANG

ELECTRIC FIELD REVERSALS

$A E \geq 500$

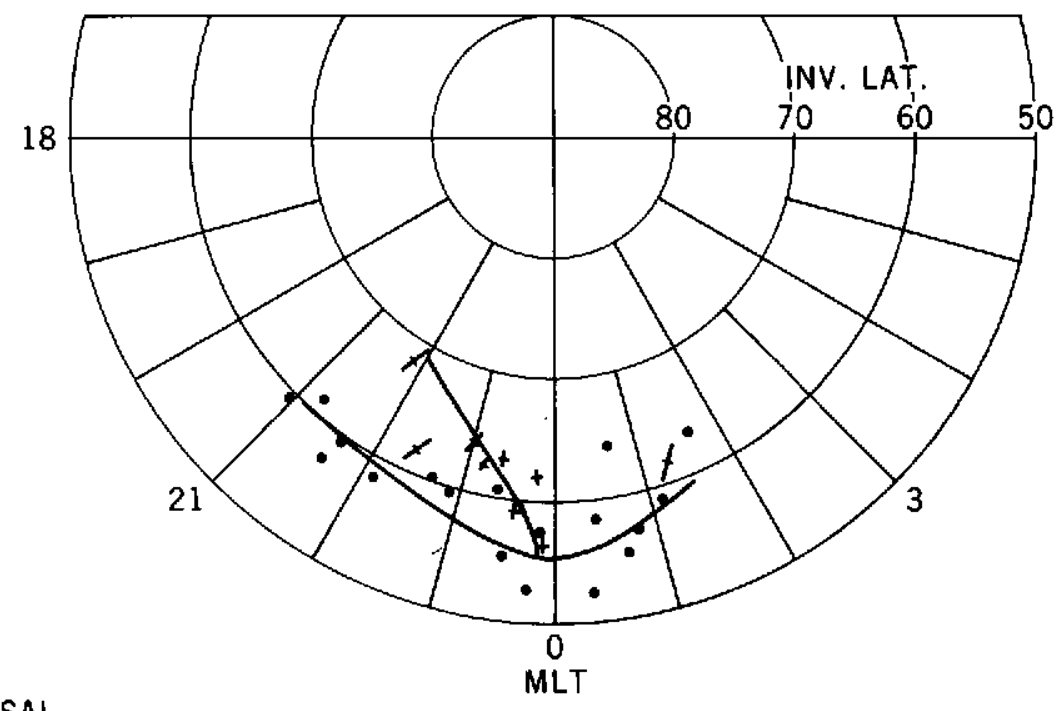

- LOWER CONVECTION BOUNDARY 

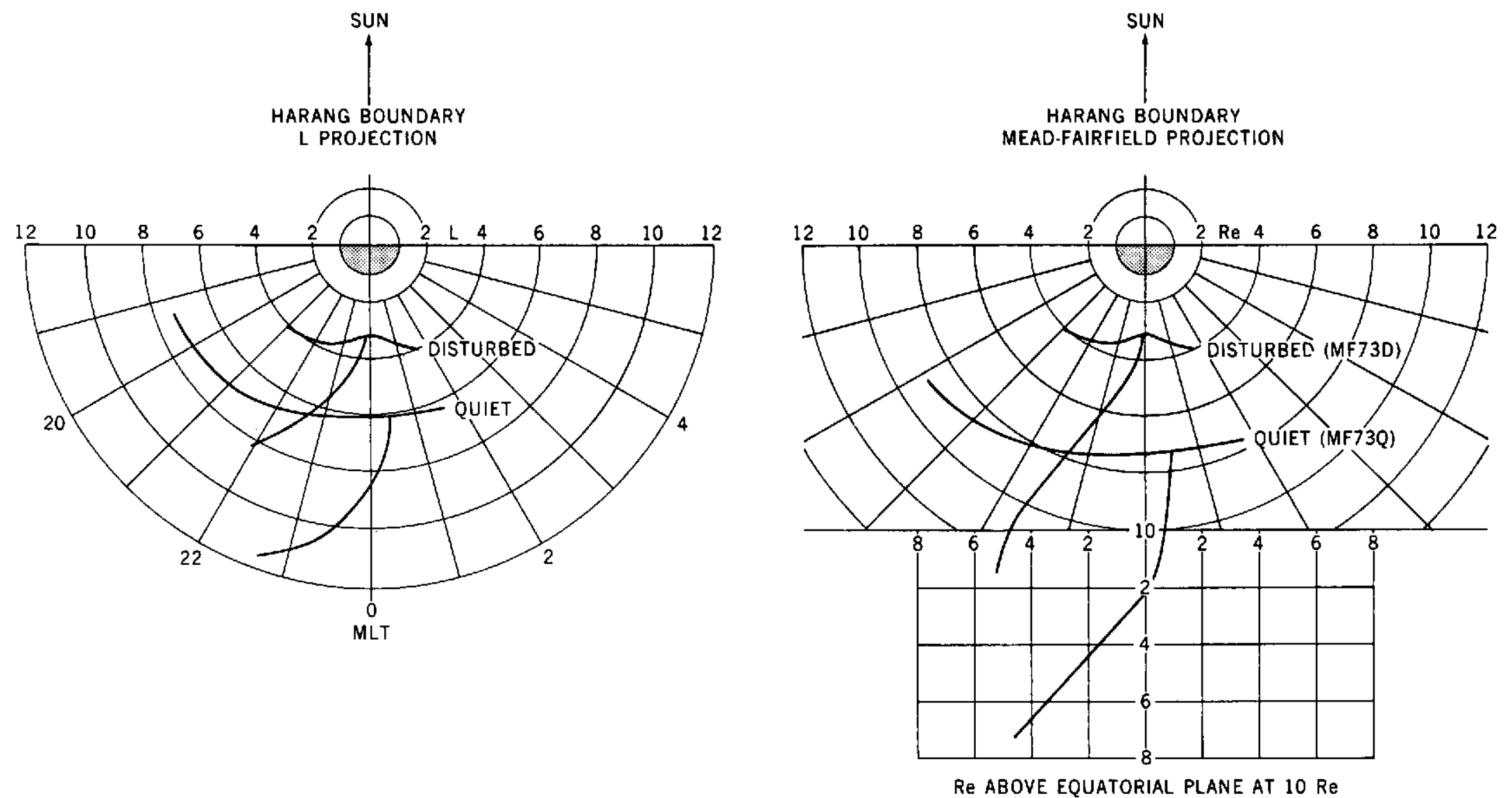

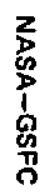

